\title{
ANÁLISE E QUANTIFICAÇÃO DA DEGRADAÇÃO DE FACHADAS POR MEIO DE FATORES DE DANOS
}

\author{
L. L. S. Batista ${ }^{1 *}$, B. S. Vale ${ }^{1}$, C. M. S. Castro ${ }^{1}$, H. S. B. Soares ${ }^{1}$, A. C. C. Lopes ${ }^{1}$, L. C. \\ Queiroz ${ }^{1}$. \\ Autor de Contato: 1sbatista.lucas40@gmail.com \\ ${ }^{1}$ Faculdade de Engenharia Civil, ITEC, Universidade Federal do Pará, Belém, Brasil
}

\begin{abstract}
RESUMO
O conhecimento e a quantificação de danos em fachadas contribuem consideravelmente na melhoria de edificações e reparo de degradações, o presente estudo busca mensurar a degradação das fachadas de um prédio, situado em Belém-PA, através do método de Fator de Danos e do Fator Geral de Danos. Os resultados mostraram os níveis de degradação que cada fachada possui e observou-se que essa metodologia se mostrou eficaz, expressando quais patologias são mais recorrentes e que a orientação delas influencia diretamente no surgimento de manifestações patológicas.
\end{abstract}

Palavras chave: Patologia; Fachada; Degradação; Dano.

\section{ABSTRACT}


The knowledge and quantification of damage to facades significantly contributes to the improvement of buildings and the repair of degradations, this study seeks to measure the degradation of the facades of a building, located in Belém-PA, through the method of Damage Factor and General Factor Damages and damages. The results showed the levels of degradation that each facade has and it was observed that this methodology proved to be effective, expressing which pathologies are more recurrent and that their orientation directly influences the appearance of pathological manifestations.

Key words: Pathology; Facade; Degradation; Damage.

\section{RESUMEN}

El conocimiento y cuantificación de daños a fachadas contribuyen considerablemente al mejoramiento de edificaciones y reparación de degradaciones, este estudio busca medir la degradación de las fachadas de un edificio, ubicado en Belém-PA, a través del método de Factor de Daño y Factor General de Daños y perjuicios. Los resultados mostraron los niveles de degradación que tiene cada fachada y se observó que esta metodología resultó ser efectiva, expresando qué patologías son más recurrentes y que su orientación influye directamente en la aparición de manifestaciones patológicas.

Palabras llave: Patología; Fachada; Degradación; Daño. 


\section{INTRODUÇÃO}

A fachada constitui-se de várias camadas que tem como objetivo principal a proteção da edificação, é inevitável que ela sofra um processo de degradação, considerando sua constante exposição a fatores deteriorantes. O processo de degradação pode dar-se de forma lenta ou acelerada, e ocorrendo, principalmente, em decorrência das condições de exposição, execução, intervenções de manutenção ou influência do comportamento das propriedades dos elementos e dos seus componentes, e da interação entre estes ao longo do tempo.

A degradação de fachadas de edifícios é uma temática comumente abordada em pesquisas científicas, e segundo Silva (2014) o conhecimento das incidências das patologias contribui para a melhoria contínua dos processos construtivos, na medida em que as informações sobre as mesmas são tratadas e divulgadas.

As análises de degradação se apresentam muitas vezes de forma subjetivas, comumente variando a depender do avaliador, esse tipo de análise é comum e não incorreta, porém uma análise quantitativa para complementar a avaliação é importante para uma visão mais ampla e objetiva. Um desses métodos quantitativos são o Fator de Danos (FD) e o Fator Geral de Danos (FGD) (Bauer et.al., 2015; Santos et.al., 2018), que através de cálculos simples, com ponderações ou não transformam a degradação em um valor numérico.

Para contribuir com estudos que promovam melhor compreensão sobre a evolução da degradação em fachadas, o presente trabalho tem como objetivo, analisar e quantificar o nível de degradação das fachadas de um prédio através dos fatores de Danos mencionados, e assim avaliar sua importância para a inspeção predial.

A princípio, produzir um mapa de danos para representar graficamente as patologias/alterações presentes na edificação, e assim utilizar essas informações para medir a degradação da fachada em valores quantitativos (Fatores de Danos) obtido por meio do levantamento das quantidades de cada dano em função da área total da fachada e também calcular o Fator Geral de Danos para a identificação das áreas mais degradadas.

\section{MATERIAIS E MÉTODOS}

\subsection{Inspeção Predial}

Para inspeção dos elementos de fachada foi utilizada a metodologia recomendada pela NBR 16747 (ABNT, 2020), de acordo com a Figura 1.

Os dados levantados foram fornecidos pelo setor responsável pelos projetos e acompanhamento de obras no local do prédio analisado.

Após a análise dos projetos fornecidos foi desenvolvida a anamnese do prédio para que posteriormente fossem executadas as vistorias com as respectivas classificações e recomendações. 


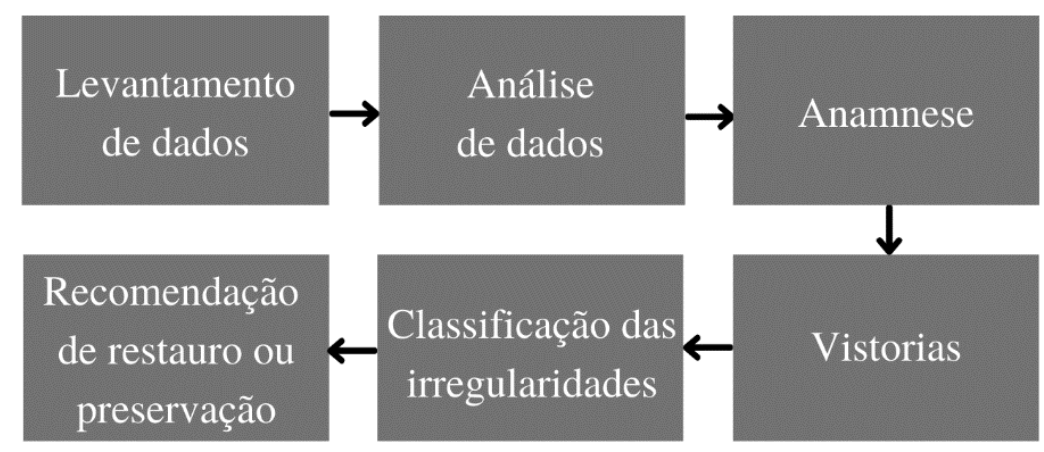

Figura 1. Fluxograma das atividades de inspeção.

\subsection{Mapa de Danos}

Para dar suporte, de forma gráfica, nas tomadas de decisões quanto as possíveis intervenções necessárias para a restauração ou reabilitação dos elementos de fachada, e para fornecer um meio para quantificar as manifestações patológicas para o cálculo do FD e do FGD. Desta forma, foi desenvolvido um mapa de danos com a representação gráfica das manifestações patológicas incidentes nas quatro fachadas.

Para elaboração do mapa de danos foi utilizado como ferramenta de desenho o AutoCAD, versão 2020 e o levantamento fotográfico obtido durante as vistorias.

\subsection{Classificação de Dano}

Para a classificação do dano encontrado nas fachadas foi realizado o cálculo do FD e FGD como indicadores de degradação. A classificação de dano apresenta uma eficiente avaliação da degradação no que se refere sua direção cardeal e localização das manifestações patológicas (Bauer et.al., 2015; Santos et.al., 2018).

A metodologia utilizada é a mesma proposta por Sousa (2008) e adaptada por Silva (2014), sendo que estes dois fatores representam de forma quantitativa o grau dos danos presentes nas fachadas analisadas. Desta forma, seu resultado final apresenta uma forte indicação para a tomada de decisão em uma possível intervenção.

\subsubsection{Fator de danos (FD)}

O FD permite realizar análises da distribuição das anomalias, identificando assim as áreas mais degradadas do ambiente estudado e os elementos construtivos mais susceptíveis a degradação, bem como permite comparar as orientações para encontrar uma tendencia de degradação (Souza, 2019). A formulação do FD é dada (Eq. 1) pela porcentagem da área afetada pela manifestação patológica em relação a área total analisada que neste caso seriam as fachadas do prédio.

$$
F D=\frac{A d}{A}
$$

Onde,

FD: Fator de dano da fachada (extensão do dano) (\%);

Ad: Área de manifestação patológica observada na fachada $\left(\mathrm{m}^{2}\right)$;

A: área total da fachada $\left(\mathrm{m}^{2}\right)$.

Para o cálculo da área de manifestação patológica foi utilizado o mapa de danos, onde a área de cada manifestação patológica foi definida. 
O Fator de Dano foi calculado separadamente para cada tipo de dano encontrado individualmente e para o total, conforme é listado abaixo:

- Fator de Dano Total (FD TOTAL)

- Fator de Dano de Microfissuras (FD - FM);

- Fator de Dano de Fissuras (FD - FI);

- Fator de Dano de Eflorescências (FD - FE);

- Fator de Dano de Manchamento (FD - FMC);

- Fator de Dano de Descolamento (FD - FDL);

- Fator de Dano de Revestimento Argamassado (FD - FR).

\subsubsection{Fator geral de danos (FGD)}

O FGD atua como uma ferramenta de cálculo do percentual de degradação e estimativa da vida útil de fachadas. Esta ferramenta de análise permite estabelecer, a partir de uma relação ponderada de diversos tipos de danos, o estágio de degradação total das amostras de fachada Silva (2014). Seu modelo de cálculo é dado a seguir:

$$
F G D=\sum \frac{\left(A_{n} \cdot K_{n} \cdot k_{c, n}\right)}{(A \cdot k)}
$$

Onde:

FGD: Fator Geral de Danos (\%);

An: Área de uma fachada afetada por $\mathrm{n}$ tipos de anomalias $\left(\mathrm{m}^{2}\right)$;

Kn: Nível de condição de $n$ anomalias contidas no intervalo $(0 ; 0,02 ; 0,20 ; 2,00 ; 4,00)$;

$\mathrm{k}$ : Constante, equivalente ao nível da pior condição $(\mathrm{k}=4,00) ; 97$

$\mathrm{kc}, \mathrm{n}$ : Custo relativo de reparação das anomalias observadas;

A: Área total de fachada analisada $\left(\mathrm{m}^{2}\right)$.

n: Referência do tipo de anomalia

A partir do mapa de danos (item 2.3), foram definidos os valores de $A_{n} \mathrm{e} A$, que são as áreas parciais e a área total, respectivamente, das manifestações patológicas existentes na edificação.

Os fatores $k \cdot k_{n} \cdot k_{c, n}$ são de ponderação que estabelecem uma graduação para cada tipo de dano em função da extensão da ocorrência. Enquanto que $k$ estabelece o máximo de degradação e varia de 0 até 4 . No presente estudo, $k$ assumiu o valor 4 , já que foi o máximo da degradação observada para todos os dados. Já $k_{n}$ varia de 0 a 4 representando o nível de dano para cada tipo.

Foram identificados na inspeção do prédio os seguintes danos:

1-Microfissuras;

2-Fissuras;

3-Eflorescência;

4-Manchamento;

5-Descolamento da camada de tinta;

6-Dano no revestimento argamassado 
Os valores de $k_{n}$ (Tabela 1) definidos para cada manifestação patológica listadas acima foram obtidos de uma adaptação de Silva (2014) de Taguchi (2010), onde existe uma classificação da gravidade para cada situação de dano provocada por alguma manifestação patológica que variam entre os números inteiros de 1 a 4, quanto maior o valor maior a gravidade da manifestação patológica.

Tabela 1 - Valores de $k_{n}$ para cada manifestação patológica.

\begin{tabular}{|c|c|}
\hline Tipo de Dano & $\boldsymbol{k}_{\boldsymbol{n}}$ \\
\hline Microfissuras & 2 \\
\hline Fissuras & 3 \\
\hline Eflorescência & 2 \\
\hline Manchamento (Biofilme) & 4 \\
\hline Descolamento da camada de tinta & 2 \\
\hline Dano no revestimento argamassado & 3 \\
\hline
\end{tabular}

Já os valores de $k_{c, n}$ (Tabela 2) foram obtidos a partir de uma proporção pelo custo de reparo mais elevado. Para a definição desse custo foram calculadas composições unitárias em relação a área, a partir do banco de preços do SINAPI - Pará (CEF, 2021). Neste trabalho, o custo mais elevado foi o tratamento de fissuras e danos no revestimento argamassado que corresponde ao valor de R\$ 92,85 , ao se considerar os matérias e mão de obra para o reparo, esse valor foi igualado a 1 e os outros valores de $k_{c, n}$ foram obtidos como a proporção do valor unitário.

Tabela 2 - Valores de $k_{c, n}$ para cada manifestação patológica.

\begin{tabular}{|c|c|}
\hline Tipo de Dano & $\boldsymbol{k}_{\boldsymbol{c}, \boldsymbol{n}}$ \\
\hline Microfissuras & 0,14 \\
\hline Fissuras & 1 \\
\hline Eflorescência & 0,18 \\
\hline Manchamento (Biofilme) & 0,31 \\
\hline Descolamento da camada de tinta & 0,32 \\
\hline Dano no revestimento argamassado & 1 \\
\hline
\end{tabular}

\section{RESULTADOS E DISCUSSÃO}

\subsection{Inspeção Predial}

A edificação consiste em um edifício de 4 pavimentos, destinado a salas de aula e salas administrativas de uma faculdade, localizado na região norte do Brasil, mais especificamente na cidade de Belém, estado do Pará. A obra deste prédio foi concluída em 2015, o que o torna uma edificação relativamente nova, com cerca de 6 anos de uso apenas. O prédio apresenta suas fachadas majoritariamente com acabamento de pintura, contudo, também possuem uma área considerável com revestimento cerâmico. Seu sistema de vedação externo é com alvenaria cerâmica.

As manifestações patológicas presentes no edifício de estudo (Figura 2) são muito similares a outras manifestações presentes em edifícios próximos, de arquitetura e métodos construtivos 
semelhantes. Indicando processos de degradação similares, provenientes de um ambiente externo em comum e/ou falhas construtivas em comum também.

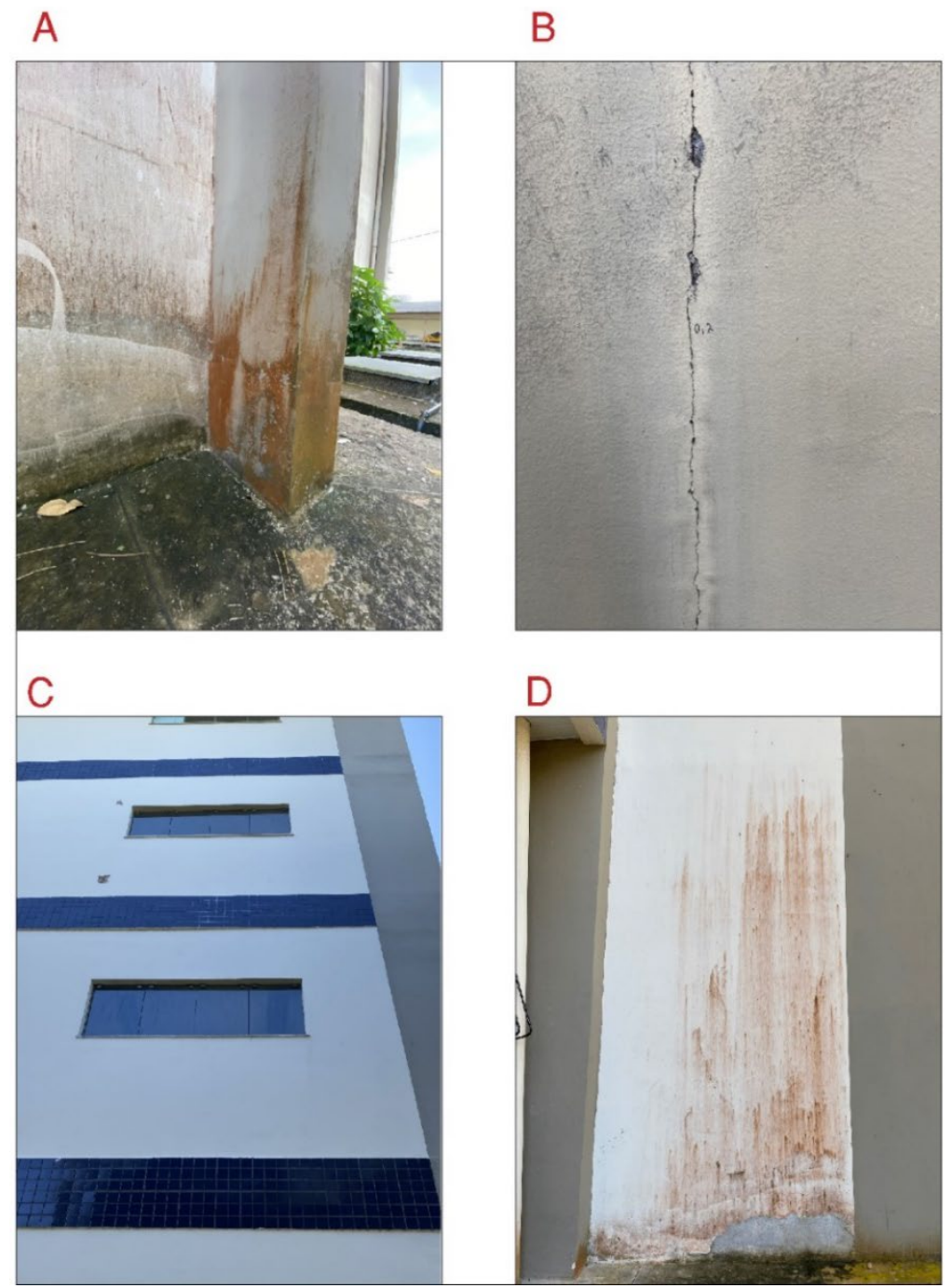

Figura 2. Fotografias de manifestações patológicas encontradas na inspeção: (A) manchamento causado por agente biológicos; (B) fissuras; (C) eflorescência nas cerâmicas e danos no reboco; (D) manchamentos e descolamento da pintura.

As comparações entre o projeto original e o construído deixam perceptível algumas modificações que não foram registradas, como detalhes arquitetônicos modificados e grades em janelas e fechamentos de vãos que não foram especificadas em projeto. Os impactos dessas mudanças serão discutidos com mais detalhes posteriormente.

O levantamento realizado no prédio deixou claro que a manifestação patológica mais visível são os manchamentos, que causam a formação de biofilme com manchamentos em tons de verde, vermelho e preto, porém também são perceptíveis o surgimento de fissuras e microfissuras, essas primeiras atingindo somente a camada da pintura, enquanto a segunda atingindo também a argamassa, comportamento similar ao analisado e discutido Thomaz (1989).

A eflorescência também foi detectada, porém somente nas áreas com revestimento cerâmico, criando manchas de coloração branca no rejunte e às vezes sobre a cerâmica.

Outras manifestações presentes foram os danos ao reboco e o descolamento da camada de pintura, entretanto, apareceram em proporções bem menores que as anteriores. 
Uma alta proliferação de biofilme apresentam um enorme risco a saúde dos usuários, pois é composta de agentes biológicos que em sua maioria são danosos ao ser humano, e grandes áreas de fachada com a presença desses agentes facilita sua contaminação, seja pelo toque ou pelo ar.

Quantificar essa e as demais manifestações patológicas presente no prédio auxilia na tomada de decisão e a visualizar melhor o grau de risco em que o prédio e os usuários se encontram (Bauer et.al., 2015).

\subsection{Mapa de Danos}

A legenda para todas as manifestações patológicas representadas nos mapas de danos está contida na Figura 3.

O mapa de danos da fachada Norte (Figura 4) representa a presença de microfissuras, manchamentos e eflorescência. Esta é uma das fachadas com maior presença de manifestações patológicas, e isso se deve provavelmente pela chuva dirigida, a direção do vento na região de Belém do Pará de acordo com o programa Sol-Ar, é predominantemente vinda da direção nordeste (Lamberts et.al., 2021).

\section{PATOLOGIAS}

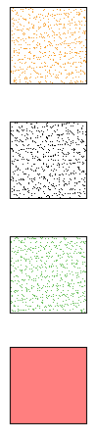

MANCHAMENTO POR UMIDADE - Laranja

MANCHAMENTO POR UMIDADE - Preto

MANCHAMENTO POR UMIDADE - Verde

DESCOLAMENTO - DESTACAMENTO

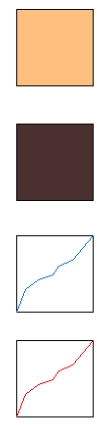

EFLORESCÈNCIA

DANO AO REBOCO

MICROFISSURAS

FISSURAS, TRINCAS E RACHADURAS

Figura 3. Legenda para a representação das manifestações patológicas nos mapas de danos.

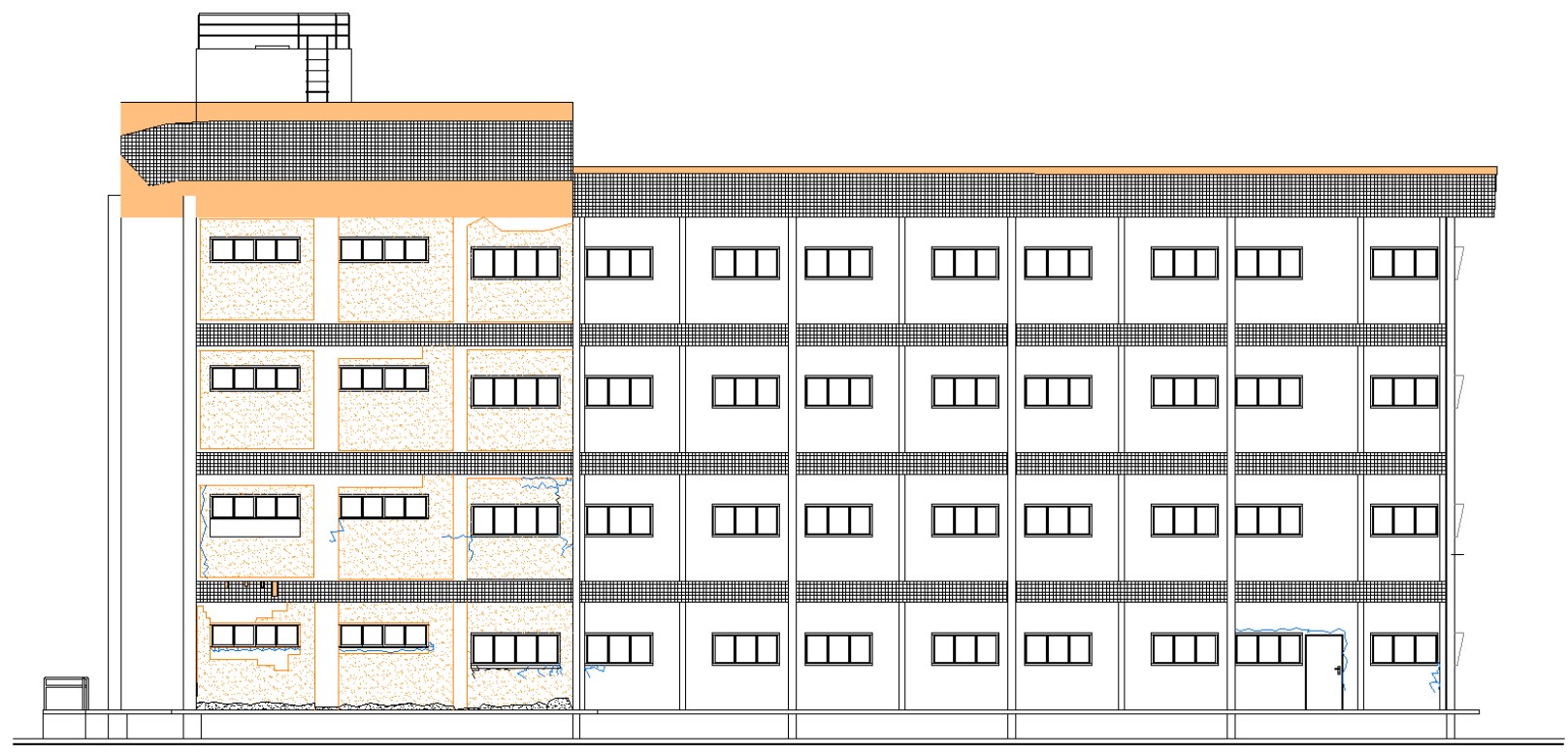

Figura 4. Mapa de danos da fachada Norte. 
A maior presença do manchamentos em determinado setor da fachada se deve ao fato dessa região não apresentar proteção suficiente quanto a chuva, ou seja, a falta de elementos arquitetônicos para diminuir a incidência da umidade sobre a fachada é a principal responsável por essa diferença (Melo-Junior, 2010). A região mais à direita possui elementos verticais e horizontais que funcionam como brises, diminuindo a incidência do sol e da chuva sobre essas fachadas (Poyastro, 2011), os elementos nada mais são que lajes e pilares projetados para fora da fachada. A Figura 5 apresenta uma fotografia da fachada Norte onde é possível visualizar a falta de detalhes arquitetônicos na região manchada, enquanto a outra região se mantém mais protegidas pelos elementos verticais e horizontais da arquitetura.

Erros construtivos também foram encontrados, os mais comuns foram nos peitoris, havia uma falta de uniformidade no assentamento, onde praticamente todos apresentavam algum erro, como falta de inclinação adequada, projeção para fora da parede e/ou comprimento além das janelas insuficientes, causando muita concentração de manchamentos nos cantos inferiores dessas esquadrias, bem como um aumento de microfissuras nessas regiões.

A fachada Leste também é a que sofre maior incidência da chuva dirigida, juntamente a fachada posicionada para a direção Norte. O mapa de danos (Figura 6) ilustra a área de manchamento devido a umidade, e é perceptível manchamentos sobre os elementos estruturais de intensidade bem menores que na alvenaria argamassada. Isso ocorre provavelmente devido à quantidade de poros bem menor do concreto estrutural. Devido a isso é formado esse padrão de manchamento na região mais à direita da fachada. O mesmo não ocorre na região mais central da fachada, essa região é mais projetada que a anterior, então a incidência da chuva tende a ser maior, neste caso a chuva pode ter facilitado o manchamento sobre os elementos estruturais, ou carregado a sujidade das áreas de alvenaria argamassada para os elementos estruturais.

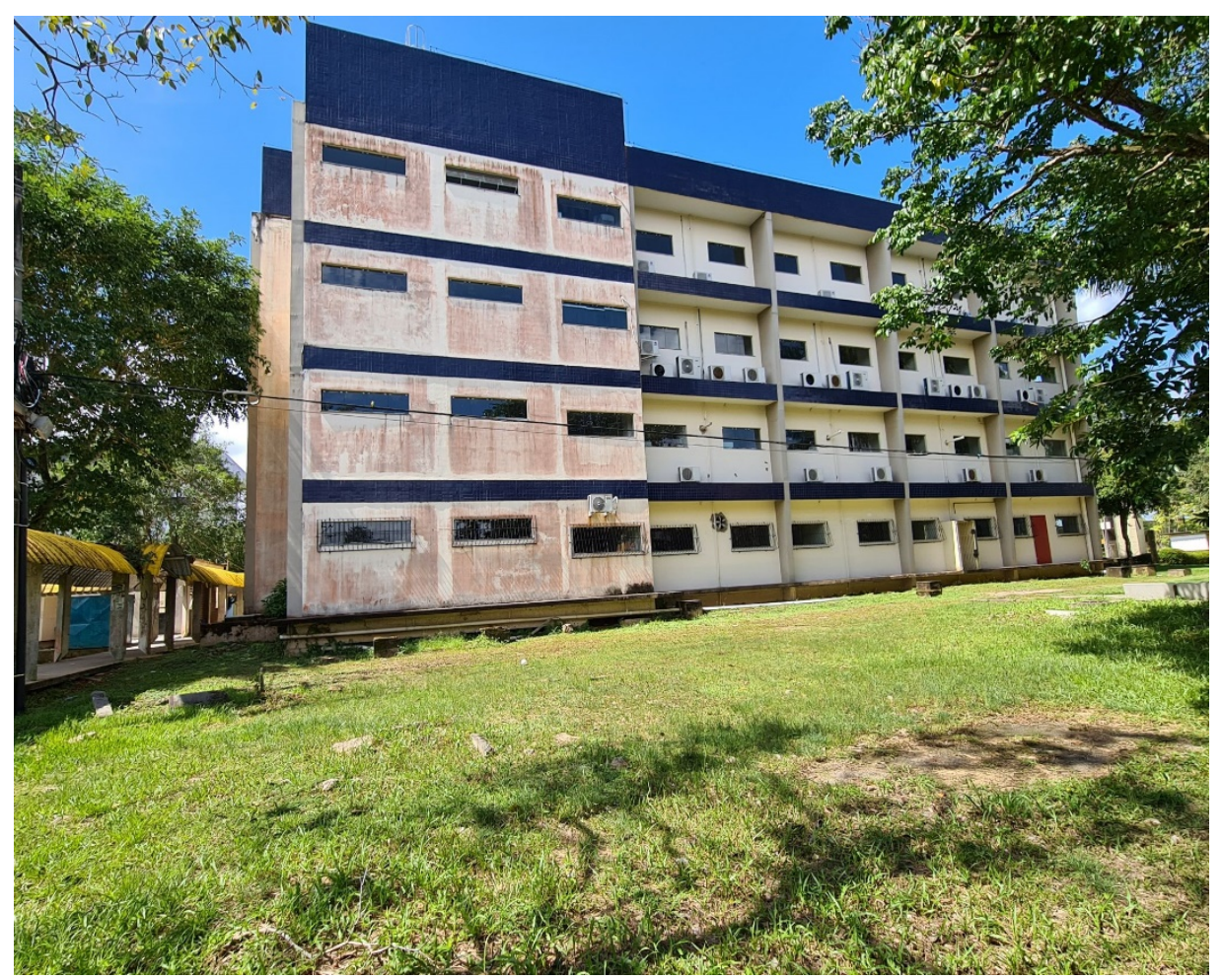

Figura 5 - Fotografia da fachada Norte 
Nesta fachada, também são perceptíveis descolamentos de pintura e massa na região central da fachada, aparentemente essa região estava fragilizada por erros construtivos e teve uma alta degradação mais localizada. Além disso, na região mais à direita desta fachada, aparecem fissuras e microfissuras em um padrão específico, indicando que são provenientes de uma diferença de deformação entre os elementos estruturais e a alvenaria utilizada para o fechamento dos vãos. É importante mencionar que este detalhe arquitetônico não foi construído como estava no projeto (Figura 7), a mudança durante a obra pode ter ocasionado problemas como a falta ou má instalação de uma amarração entre a alvenaria e os elementos estruturais, causando essas manifestações.

As fachadas Oeste e Sul (Figura 8 e 9), apresentam manifestações patológicas similares às anteriores, porém em menores quantidades, o que era esperado, devido a menor incidência de chuva dirigida. Mesmo assim, a falta de elementos construtivos que diminuam a incidência da chuva ainda é necessária em algumas regiões que apresentam manchamentos e eflorescência, além disso são perceptíveis os mesmos erros de execução no assentamento dos peitoris das janelas.

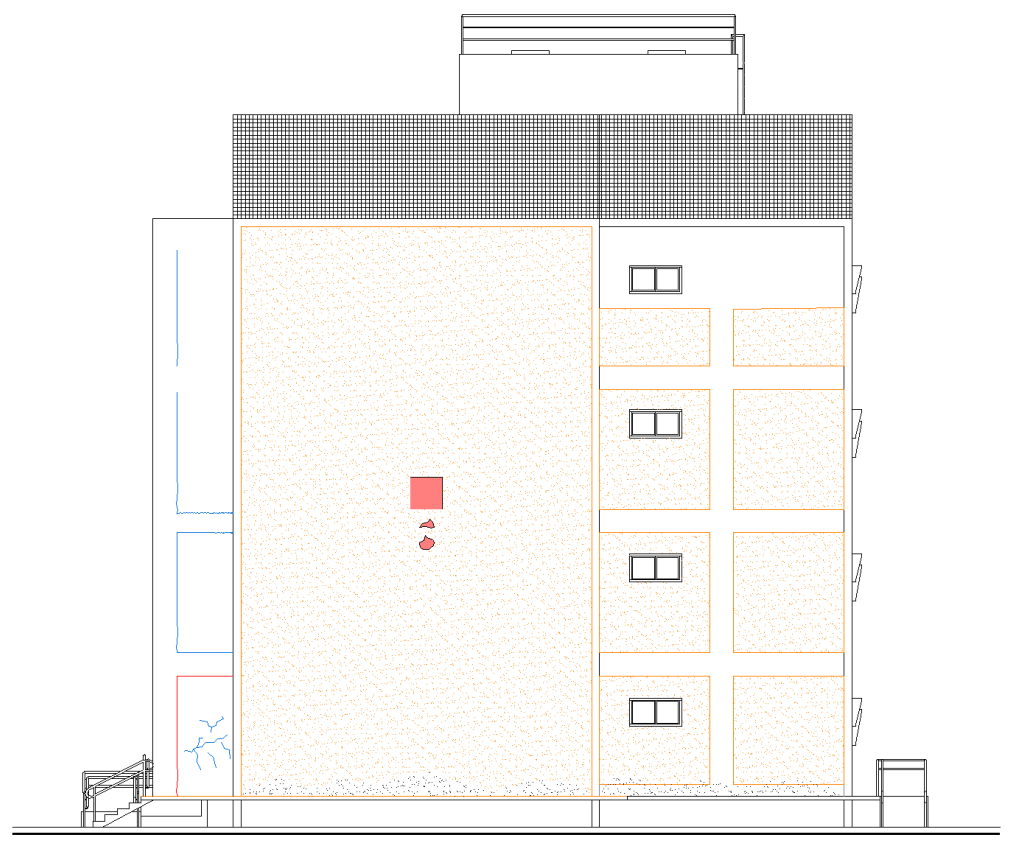

Figura 6. Mapa de danos fachada Leste
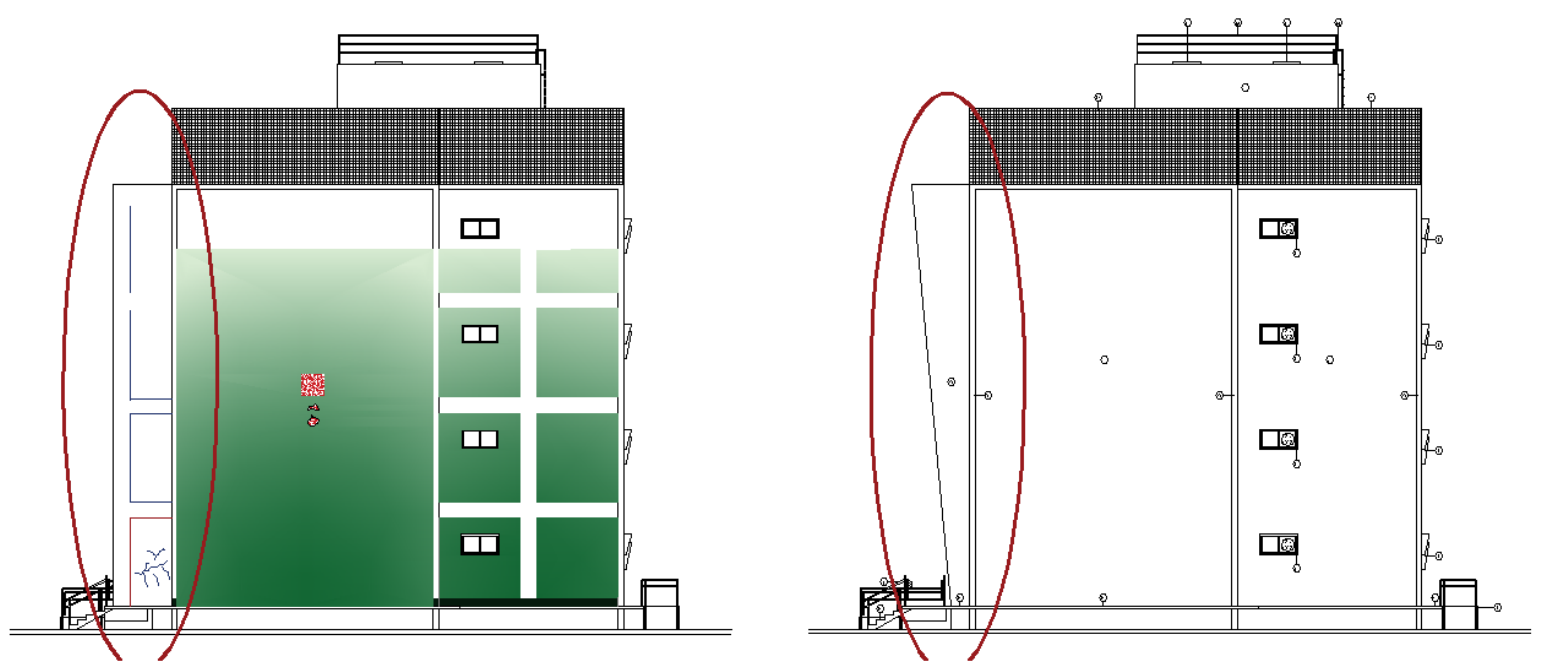

Figura 7. Comparação entre o construído e o projeto respectivamente. 
A fachada Oeste apresenta pequenos danos no revestimento argamassado (Figura 2C), sendo estes pontuais e provavelmente foram causados na execução ou por alguma intervenção posterior.

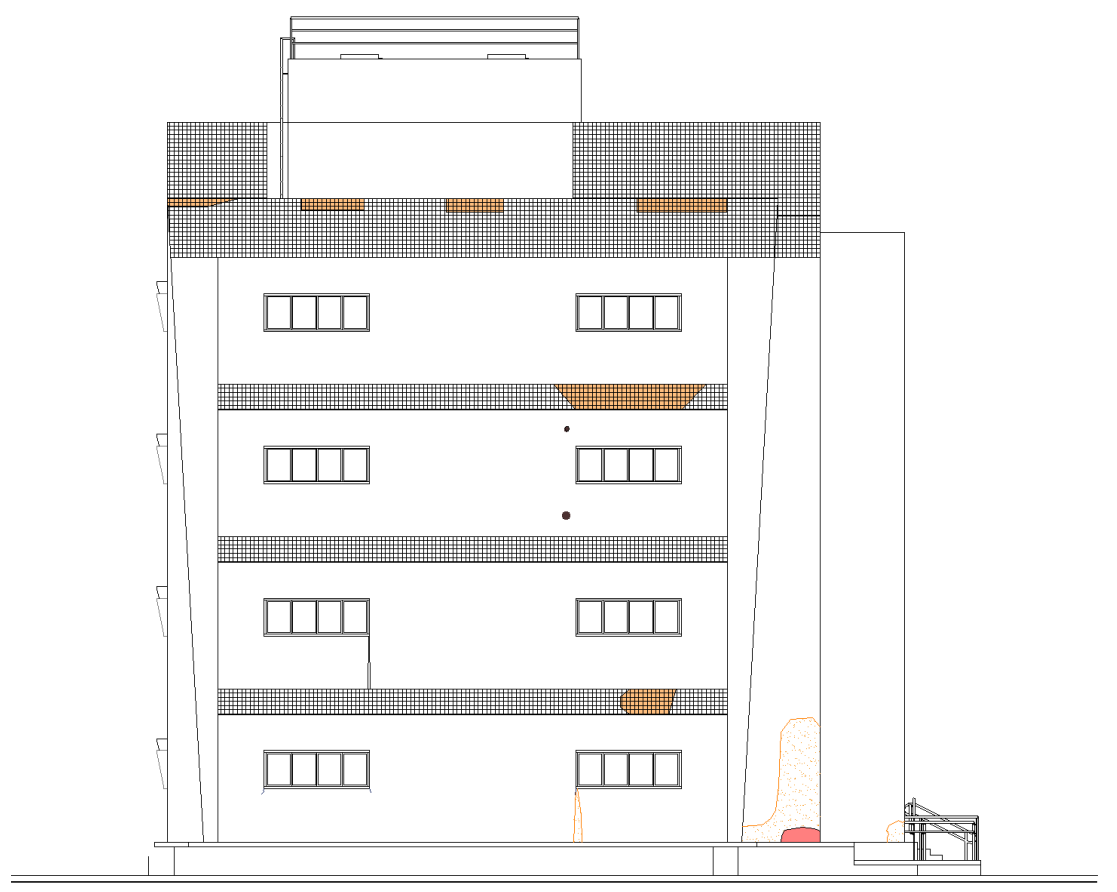

Figura 8. Mapa de danos fachada Oeste.

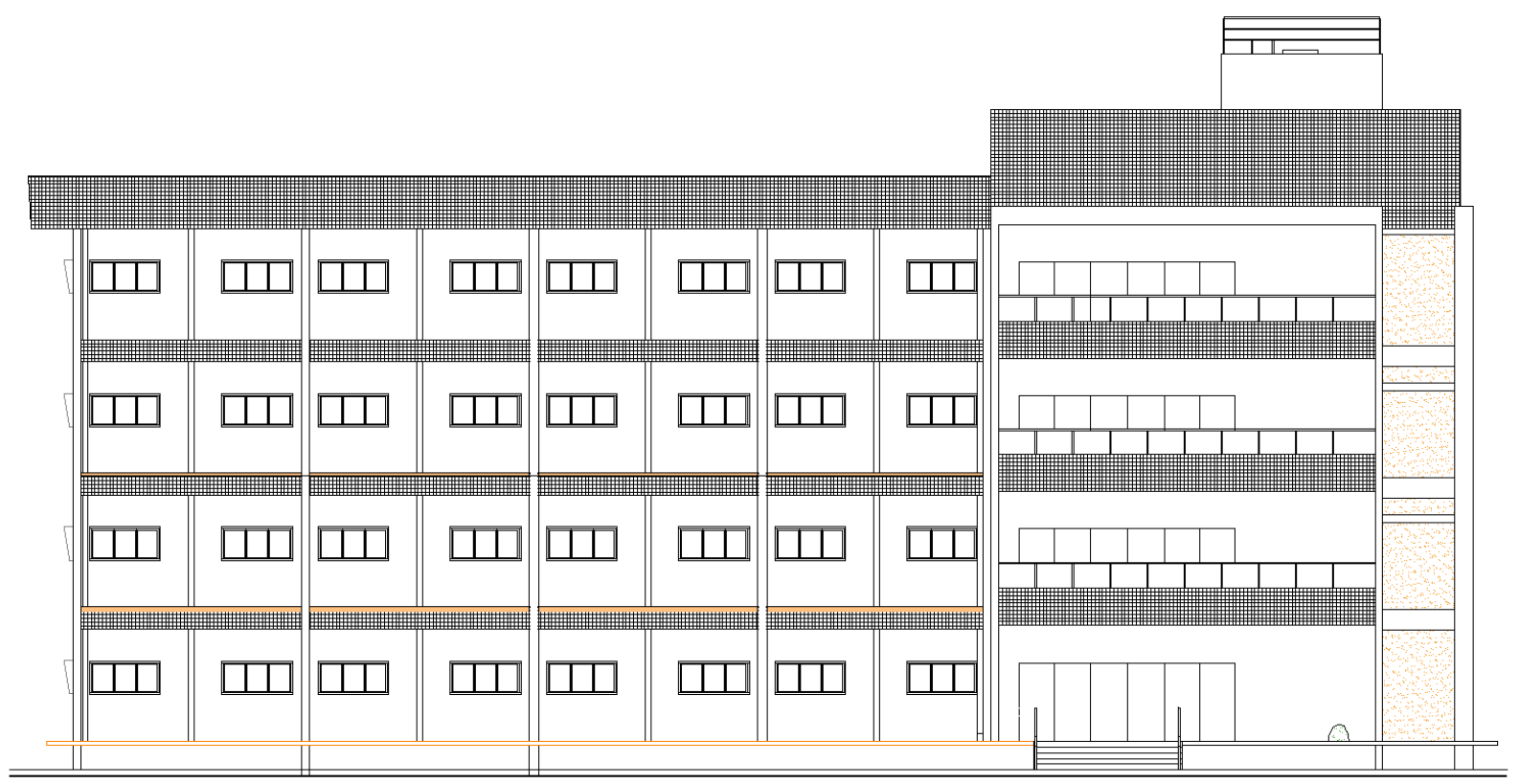

Figura 8. Mapa de danos fachada Sul

A fachada Sul apresenta maiores manchamentos na região mais à direita, pois é a única região que não apresenta nenhum detalhe arquitetônico que diminua a incidência da chuva, causando um manchamento quase que contínuo sobre toda sua extensão, com exceção dos elementos estruturais, que nesse caso são as vigas dos pavimentos e vigas da escada. 
Fica evidente que a presença de detalhes arquitetônicos pode diminuir a ocorrência de algumas manifestações patológicas nas edificações (Chong e Low, 2006). Fachadas com detalhes que diminuem a incidência de agentes agressivos como a chuva e o sol tendem a apresentar manchamentos em menores quantidades ou até nenhum manchamento.

Além de uma análise mais subjetiva ao visualizar de forma ampla as fachadas e suas manifestações patológicas, a identificação realizada através do mapa de dano tem uma função importante em quantificar as áreas afetadas no cálculo do FD e do FGD.

\subsection{Fator de Dano}

Os resultados do FD (Tabela 3) indicam que o prédio analisado sofre principalmente com os manchamentos, gerando camadas enormes de biofilme ao longo das fachadas, que ocupam 7,49\% das fachadas. Em seguida está a eflorescência, ocupando quase 1\% das fachadas. As demais manifestações ocupam porcentagens bem abaixo de $1 \%$, indicando que elas não apresentam uma urgência no reparo.

Esta análise é importante, pois representa uma realimentação da situação do prédio, identificando as falhas de projeto e/ou execução para que não sejam repetidas (Sousa e Abiko, 1997; Othman, 2007).

Desta forma, o manchamento em conjunto com a proliferação de agentes biológicos, além de apresentar a maior área de ocorrência, também é considerado a mais grave devido a extensão de biofilme e dos danos que ele pode causar a integridade da construção e aos usuários como mencionado anteriormente, o que torna essa anomalia a mais urgente a ser tratada (Pereira et./al., 2015). No entanto, como já discutido, o FD apresenta a ocupação das manifestações patológicas, não pondera sua importância, por isso o cálculo do FGD faz-se necessário.

\begin{tabular}{|c|c|c|}
\hline \multicolumn{3}{|c|}{ Tabela 3 - Valores de FD para cada manifestação patológica. } \\
\hline Classificação & Tipo de Dano (n) & FD \\
\hline 1 & Microfissuras & $0,88 \%$ \\
\hline 2 & Fissuras & $0,29 \%$ \\
\hline 3 & Eflorescência & $11,24 \%$ \\
\hline 4 & Manchamento (biofilme) & $87,24 \%$ \\
\hline 5 & Descolamento da camada de tinta & $0,34 \%$ \\
\hline 6 & $\begin{array}{r}\text { Dano no revestimento } \\
\text { argamassado }\end{array}$ & $0,01 \%$ \\
\hline
\end{tabular}

O resultado do FGD foi de 2,44\%, indicando um nível de degradação consideravelmente baixo. Porém esse valor refere-se a todas as fachadas, inclusive aquelas pouco degradadas e ao se utilizar esse fator nesse formato pode gerar uma falsa sensação de baixa degradação. Devido a isso, o cálculo do FGD foi refeito considerando somente as fachadas leste e norte por serem as mais degradadas. O valor de FGD foi de 9\%, mais que o triplo do valor anterior, indicando um nível de degradação maior. E se for analisado ainda as fachadas separadas, percebe-se que a fachada Leste 
apresenta o maior valor de FGD, correspondendo a $28 \%$, ou seja, apresentando altos níveis de degradação.

Desta forma, fica claro que a orientação das fachadas influencia diretamente no Fator Geral de Degradação das mesmas, além disso, os fatores de dano ou degradação se tornam grandes indicadores para a tomada de decisão ao se cogitar uma intervenção, assim como se torna uma ferramenta para auxiliar na identificação das causas por trás das manifestações, como no caso deste trabalho, com um FGD maior nas fachadas Leste e Norte, indicando que a chuva dirigida que provem dessas direções é provavelmente o principal agente de degradação dessas fachadas.

\section{CONCLUSÕES}

As análises dos fatores de danos foram feitas com o objetivo de quantificar e obter-se uma visão coletiva sobre as deteriorações presentes nas fachadas. Os resultados do FD e FGD mostrou-se eficiente na representação das degradações, considerando que os fatores admitidos permitiram estabelecer que os manchamentos por umidade é a manifestação patológica mais recorrente nas fachadas analisadas, sendo que sua intensidade de degradação segue a ordem: Leste, Norte, Sul e Oeste (maior para menor ), já as outras manifestações patológicas encontradas mostrou-se menos recorrente, tendo como causas problemas de execução, diferenciação entre materiais utilizados nos elementos, dentre outros.

De uma forma geral, a orientação das fachadas influencia diretamente no fator geral de degradação das mesmas, além disso, os fatores de dano ou degradação se tornam grandes indicadores para a tomada de decisão ao se cogitar uma intervenção, assim como se torna uma ferramenta para auxiliar na identificação das causas destas anomalias, como no caso deste trabalho.

\section{AGRADECIMENTOS}

Os autores agradecem a Universidade Federal do Pará pela disponibilização de documentos para o desenvolvimento deste trabalho, assim como pelo apoio a pesquisa desenvolvida.

\section{REFERÊNCIAS}

ABNT. (2020). NBR 16747: Inspeção predial - Diretrizes, conceitos, terminologia e procedimento. Rio de Janeiro.

Bauer, E.; Castro, E. K.; Silva, M. N. B. (2015), Estimate of the facades degradation with ceramic cladding: Study of Brasilia buildings. Cerâmica, v. 61, n. 358, p. 151-159.

Caixa Economica Federal (CEF). (2021), Referencia de Isumos e composições de preço. Disponivel em: https://www.caixa.gov.br/

Chong, W.; Low, S. (2006), Latent Building Defects: Causes and design strategies to prevent them. Journal of Performance of Constructed Facilities. v. 20, n. 3, p. 213-221.

Lamberts, R.; Maciel, A. A.; Ono, E. (2021), “Sol-Ar.” Laboratório de Eficiência Energética das Edificações.

Melo Junior, C. M. (2010), Influência da chuva dirigida e dos detalhes arquitetônicos na durabilidade de revestimentos de fachada. Dissertação de Mestrado. Universidade Federal de 
Goiás.

Othman, A. (2007), Maintenance management and generating sustainable values in construction projects. Proceedings of the 1st Construction Industry Research Achievement International Conference (CIRAIC 2007).

Pereira, C.; De Brito, J.; Correia, J. R. (2015), Building Characterization and Degradation Condition of Secondary Industrial Schools. Journal of Performance of Constructed Facilities, v. 29, n. 5, p. 04014128.

Poyastro, P. C., (2011), Influência da volumetria e das condições de entorno da edificação no manchamento e infiltração de água em fachadas por ação de chuva dirigida. Dissertação de Mestrado. Universidade Federal do Rio Grande do Sul.

Santos, D. G. Macêdo, M. S. P. H., Souza, J. S. e Bauer, E. (2018), Mensuração e distribuição de patologias na degradação em argamassa. Gestão e Gerenciamento, v. 2, n. 1, p. 13.

Silva, M. De N. B. (2014), Quantitative evaluation of degradation and service life of facade coatings - application to Brasilia/DF's case. Tese de Doutorado. University of Brasilia.

Sousa, R. de; Abiko, A. (1997), Metodologia para desenvolvimento e implantação de sistemas de gestão da qualidade em empresas construtoras de pequeno e médio porte. Escola Politécnica da USP, São Paulo.

Sousa, R. D. B. (2008), Previsão da vida útil dos revestimentos cerâmicos aderentes em fachada. Dissertação de Mestrado. Universidade Técnica de Lisboa.

Souza, J. S. (2019), Impacto dos fatores de degradação sobre a vida útil de fachadas de edifícios. Tese de Doutorado. Universidade de Brasília.

Taguchi, M. K. (2010), Avaliação e qualificação das patologias das alvenarias de vedação nas edificações. Dissertação de Mestrado. Universidade Federal do Paraná.

Thomaz, E. (1989), Trincas em edifícios: causas, prevenção e recuperação. PINI, 1. ed. São Paulo. 